\title{
A NEW BASIC CREEP MODEL COUPLED WITH A THERMO- MECHANICAL MODEL FOR THE NUMERICAL SIMULATION OF THE TIME-DEPENDENT BEHAVIOUR OF CONCRETE STRUCTURES
}

\author{
TIAGO S. VALENTE ${ }^{*}$, A. VENTURA-GOUVEIA ${ }^{\dagger}$ AND JOAQUIM A. O. BARROS ${ }^{\dagger \dagger}$ \\ "CiviTest Pesquisa de Novos Materiais para a Engenharia Civil, Lda. \\ V. N. Famalicão, Braga Portugal \\ e-mail: tiagovalente@ civitest.com \\ ${ }^{\dagger}$ Polytechnic Institute of Viseu \\ Viseu, Portugal \\ e-mail: ventura@estgv.ipv.pt \\ ${ }^{\dagger}$ University of Minho \\ Guimarães, Portugal \\ e-mail: barros@ civil.uminho.pt
}

Key words: Finite element method, concrete maturation, shrinkage, creep, cracked concrete

\begin{abstract}
This work is dedicated to the description of a new basic creep model that was developed and integrated in a thermo-mechanical model already available in a FEM-based software - FEMIX. The basic creep model is based on the Dirichlet series expansion of the Double Power Law (DPL) approach, and is capable of predicting the aging creep behaviour of cement based materials (CBM) since early ages. Based on experimental results, the model resorts to a non-linear least square datafitting operation to various loading ages creep compliance curves, and determines a set of model defining coefficients to simulate the aging viscoelastic properties of any CBM. This model was integrated with a thermo-mechanical model capable of simulating maturation, shrinkage and cracking phenomena of CBM. The good predictive performance of the implemented model is appraised by simulating experimental tests at material and structural scale.
\end{abstract}

\section{INTRODUCTION}

When in service all cement based materials $(\mathrm{CBM})$, like concrete and mortar, experience the effect of instantaneous and time-dependent deformations, therefore they have a viscoelastic nature [1]. When submitted to a constant sustained stress, the time-dependent deformation of a CBM is composed by a slow and continuous increase of deformation with time, at a decreasing rate, but without a maximum limiting bound. This phenomenon is commonly referred as creep. When the applied stress level is less than of about $40-50 \%$ of the material strength limit, the viscoelastic behavior of a CBM can be considered linear when the principle of superposition and proportionality are fulfilled [2]. This means that there is a linear relationship between stress and strain [3], $\varepsilon(t)=J\left(t, t_{0}\right) \cdot \sigma\left(t_{0}\right)$, where $J\left(t, t_{0}\right)$ is the uniaxial creep compliance function that characterizes a given CBM. The creep compliance is a function that represents the 
instantaneous plus the creep deformation at time $t$, caused by a unitary stress acting since time $t_{0}$.

According to [4] and [5], some of the mechanisms that control creep behaviour of $\mathrm{CBM}$ are: i) sliding of the colloidal sheets in the cement gel between the layers of absorbed water - viscous flow; ii) Expulsion and decomposition of the interlayer water within the cement gel - seepage; iii) Elastic deformation of the aggregate and the gel crystals as viscous flow and seepage occurring within the cement gel - delayed elasticity; iv) Local fracture within the cement gel involving the breakdown (and formation) of physical bonds - microcracking; v) Mechanical deformation theory; vi) Plastic flow; vii) Solidification theory; viii) Microprestress of creep sites in cement gel microstructure; viii) dissolution-precipitation process that acts at nanoscale contact regions of calcium-silicate-hydrates $(\mathrm{C}-\mathrm{S}-\mathrm{H})$ particles.

When submitted to sustained stress for long periods of time, concrete creep deformation can reach about $50 \%$ in the first $2-3$ months and about $90 \%$ in 2-3 years after loading [6]. Afterwards, the strain rate is almost negligible [6].

It is known that creep deformation of CBM can be decomposed in two parts: a) basic creep; b) drying creep. The basic creep is associated to the stress state of the material and can be identified in sealed specimens in which all moisture interactions with the external environment are avoided. Basic creep is considered as a material constitutive property and independent from the specimen's size and shape [7]. The drying creep is related to the time dependent deformation coupled with the drying effect of the CBM specimens, and is experimentally determined after subtracting shrinkage, elastic, thermal and basic creep components from the total measured strain [6], [7].

The creep deformation magnitude and rate of change are influenced by different factors such as: material composition, and environmental and loading conditions [6], [8]. In general, the creep deformation of high strength concrete is lower than normal strength counterparts. Additionally, the higher aggregate content and maximum aggregate size, and the lower water-cement ratio, also reduce the creep deformation of CBM [6]. Regarding the element geometry, the creep is more significant in thin structural specimens, such as slabs, which exhibit higher surfacearea/volume ratios [6], [9]. In addition to relative humidity, the environment temperature is also an important factor in creep phenomena. The rise in temperature increases the deformation of the cement paste and accelerates drying, and consequently increases the creep. The dependence of creep deformations to the temperature is more pronounced in high temperatures and has low relevance between $0^{\circ} \mathrm{C}$ and $20^{\circ} \mathrm{C}$. At room temperature of $40^{\circ} \mathrm{C}$, the creep in concrete has been reported to be $25 \%$ higher than that at $20^{\circ} \mathrm{C}$ [6].

The creep deformation of CBM is highly influenced by the loading age of the specimens. For early ages, the creep strain magnitude is higher than for specimens loaded at later ages, as long as the specimens are submitted to equal stress levels. This behavior is designated by aging (or maturing) and the solidificationmicroprestress theory is being used for its physical explanation [10], [11], [12], [13].

Although the main topics in CBM creep assessment are related with compressive stress states, the consideration of creep effect in tension and bending is of great interest, especially in the analysis of the cracking risk of structures since early ages, due to the effects of shrinkage, temperature variations and load actions. The main mechanisms that rule the behavior of CBM creep in tension are common to creep in compression.

The most used creep models are: (i) the Double Power Law (DPL) [14]; (ii) the Model Code 2010 model (MC2010) [15]; (iii) the B3 model [16]; (iv) and its recent updated form, the B4 model [17]. The DPL and MC2010 models follow the classical approach that treats the material parameters involved in creep as empirical functions of time and loading age; the B3 and B4 models that follows a phenomenological approach, where the materials parameters are determined based on the existing physical, chemical and 
thermodynamic understanding on concrete creep phenomenon and its microstructure.

According to [18], the B4 model outputs the most accurate creep predictions when applied to the Northwestern University creep database, compared to the B3 model and MC2010, amongst other models.

The numerical simulation of concrete structures sensitive to creep requires the adoption of adequate constitutive models for accurate simulation of the viscoelastic, cracking, maturing and thermal behaviour of the involving cement based materials. In the particular case of concrete structures submitted to significant stress states at concrete early age, such happens in prefabricated prestressed structural elements, the influence of the concrete creep effect on the structural response can be significant in terms of estimating initial and long term damage due to cracking occurrence.

In the present work, a new creep model is developed and integrated with an existing thermo-mechanical approach already available in FEMIX computer program [19] in order to couple maturation, shrinkage, creep, temperature variation and cracking. This model is described and its predictive performance appraised.

\section{CONSTITUTIVE MODELS}

\subsection{Introduction}

The present section is mainly dedicated to the description of a new aging creep compliance model, herein designated by the acronym ACC. This model is integrated in FEMIX computer program with a thermo and maturation models described in [19], shrinkage models (Eurocode 2 [20] or B3 [21] models) detailed in [22], and a 3D multidirectional fixed smeared crack model (MFSCM) described in [22] for simulating the time dependent phenomena in cracked concrete since its early age up to its hardened stage.

\subsection{ACC model}

According to the superposition principle, the total strain $\varepsilon(t)$ caused by a given stress history $\sigma(t)$ can be obtained by decomposing the history in small increments $d \sigma\left(t_{0, i}\right)$ applied at various time instants $t_{0, i}$, adding the corresponding strains $\left(\int_{0}^{t} J\left(t, t_{0, i}\right) \cdot d \sigma\left(t_{0, i}\right)\right)$ and the stress independent strains $\varepsilon_{0}(t)$, resulting in the following Stieltjes integral [1], [6], [23]:

$$
\varepsilon(t)=\int_{0}^{t} J\left(t, t_{0, i}\right) \cdot d \sigma\left(t_{0, i}\right)+\varepsilon_{0}(t)
$$

The $J\left(t, t_{0}\right)$ can be transformed in a sum of products of functions of $t$ and $t_{0}$, called Dirichlet series (or Prony series) [24], [25]:

$$
J\left(t, t_{0}\right)=\frac{1}{E_{s}\left(t_{0}\right)}+\sum_{\mu=1}^{N} \frac{1}{E_{\mu}\left(t_{0}\right)}\left(1-e^{-\frac{\left(t-t_{0}\right)}{\tau_{\mu}}}\right)
$$

where $E_{s}\left(t_{0}\right)$ (influences the instantaneous response of the creep function) and $E_{\mu}\left(t_{0}\right)$ are coefficients dependent of the loading age $t_{0}$ (Kelvin chains), both with units of elastic moduli; $\tau_{\mu}$ are constants called retardation times; $\mu$ is the number of series; and $N$ is the total number of series.

The ACC model is a basic creep model based on the Dirichlet series expansion of the DPL model [14], capable of predicting the aging creep behavior of CBM since early age. According to ACC model, the modulus of each Kelvin chain, $E_{\mu}\left(t_{0}\right)$, in Eq. (2) is obtained from [27]:

$$
\begin{gathered}
\frac{1}{E_{\mu}\left(t_{0}\right)}=\rho \cdot b_{\mu}\left(\frac{\tau_{1}}{0.002}\right)^{n_{\mu}} \frac{\varphi_{1, \mu}}{E_{s}\left(t_{0}\right)} 10^{n_{\mu}(\mu-1)} t_{0}^{-m_{\mu}} \\
\rho=\left\{\begin{array}{l}
1.0, \text { for } \mu<N \\
1.2, \text { for } \mu=N
\end{array}\right.
\end{gathered}
$$

where $b_{\mu}, n_{\mu}, \varphi_{1, \mu}$ and $m_{\mu}$ are the coefficients of the model calibrated from the experimental creep test data.

While in the original model [14], the defining coefficients are fixed for all Kelvin chains, the ACC model uses different values for these coefficients in each Kelvin chain. The equation to compute the modulus of the isolated spring of the Kelvin generalized model $E_{s}\left(t_{0}\right)$ is also different than the proposed in the 
original model. Its value is determined with the following equation:

$$
E_{s}\left(t_{0}\right)=\lambda \cdot E\left(t_{0}\right)
$$

where $E\left(t_{0}\right)$ is the Young Modulus of the material evaluated at the loading age $t_{0}$ and $\lambda$ is the scaling factor $(\lambda \geq 1.0)$. The $E_{s}\left(t_{0}\right)$ represents the true elastic instantaneous response of the material, while the conventional elastic modulus $E\left(t_{0}\right)$ corresponds to a modulus obtained from compression tests with loading durations of 1 to 5 minutes, that incorporates the instantaneous and short-time creep response of the material within this time interval [27].

To determine the defining coefficients of the ACC model $\underline{\psi}=\left[\begin{array}{llll}b_{\mu} & n_{\mu} & \varphi_{1, \mu} & m_{\mu}\end{array}\right], \mu=1, \ldots, N$, a nonlinear least square method (NLSM) is applied to the experimental creep compliance curves. This fitting procedure considers the following input data: $N, \tau_{\mu}, E\left(t_{0}\right)$, and $\lambda$.

The number of Kelvin chains should be adequately selected, so that their corresponding retardation times cover the entire scale of the simulation [23]. According to [23], the retardation times should be uniformly spread over the logarithmic time scale.

The objective function of the NLSM takes the following form:

$$
\Phi=\sum_{i=1}^{L} \sum_{j=1}^{M_{L}}\left(J\left(t_{j, i}, t_{0, i}\right)_{\text {num }}-J\left(t_{j, i}, t_{0, i}\right)_{\text {exp }}\right)^{2}
$$

where $L$ is the total number of experimental creep compliance functions to be fitted; $M_{L}$ is the number of discrete points considered for fitting each creep function (from experimental data); $J\left(t_{j, i}, t_{0, i}\right)_{\exp }$ are the experimental values of the creep compliance corresponding to the loading age $t_{0, i}$ for each time step $t_{j, i}$; $J\left(t_{j, i}, t_{0, i}\right)_{n u m}$ are the creep compliance estimated values determined according to Eqs. (2) and (3). The meaning of variables $L$ and $M_{L}$ is exemplified in Figure 1 as illustrative case. The number of discrete points $M_{L}$ should be enough to accurately capture the trend of each creep function. The coefficients of the model can be obtained through the minimization of the following the equation:

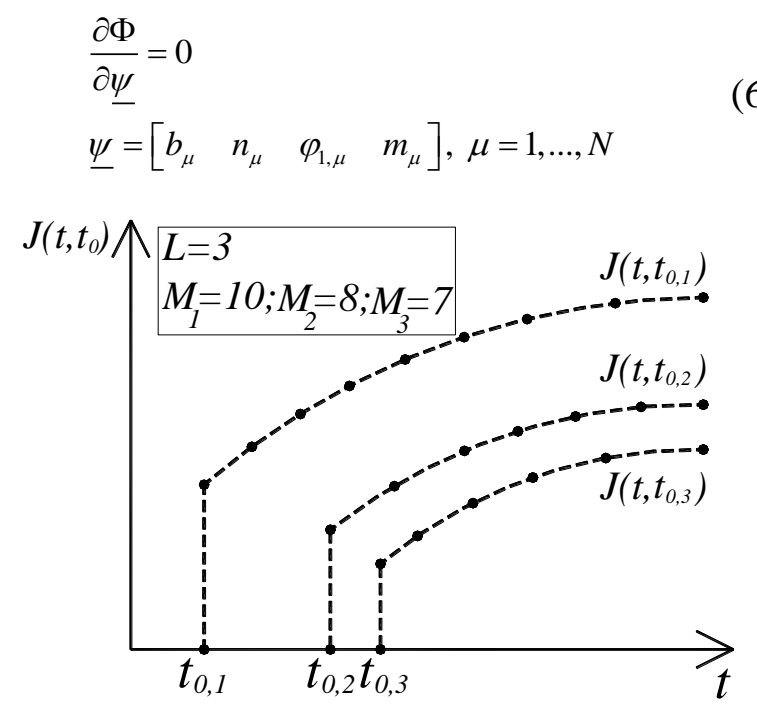

Figure 1: Example of three creep functions ( $L=3$ ) to be fitted, where each function is defined by different number of points: $M_{1}=10 ; M_{2}=8 ; M_{3}=7$.

The good predictive performance of ACC model at material level was appraised regarding its application for predicting, since early age, the creep behavior of epoxy adhesive [26] and concrete samples [28], as well as in sets of experimental creep data extracted from the Northwestern University data bank [29], [30], [31]. Furthermore, a comparison between the evolution of basic creep with time duration and loading age of the ACC and B4 models is performed. The creep compliance curves of the B4 model [29] was determined considering the following sets of parameters: i) parameters prediction based on concrete strength; ii) cement type $\mathrm{R}$; iii) $E(t=28$ days $)=24.87 \mathrm{GPa}$; iv $)$ $m=0.5$; v) $n=0.1$; vi) $\%=0.6$; vii) $\alpha=7$; viii) $\overline{f_{c}^{28}}=28 M P a$. The defining coefficients of the ACC model were determined by the NLSM to fit the B4 model creep curves, considering the following parameters: i) $E(t=3$ days $)=27.7 \mathrm{GPa}$;

ii) $E(t=7$ days $)=30.8 \mathrm{GPa}$;

iii) $E(t=28$ days $)=34.0 \mathrm{GPa}$;

iv) $E(t=200$ days $)=36.2 \mathrm{GPa}$;

v) $E(t=2000$ days $)=37.1 \mathrm{GPa}$; vi) $\lambda=1.75$; vii $)$ $N=10$; viii) $\tau_{1}=1 \times 10^{-3}$; ix) $\tau_{\mu}=\tau_{1} \cdot 10^{\mu-1}$ for $\mu=2$ to $N$. As can be seen in Figure 2 the ACC model reveals a good agreement with the B4 model particularly for short and medium-term time duration. However, for long-term creep estimation, the ACC model exhibits a deviation 
from the B4 creep curves. This shortcoming of the model is related with the different mathematical formulation of the models. For long-term duration the B4 model approaches a logarithmic function, while the ACC model, that is based on the original DPL model, uses power curves for all time durations.

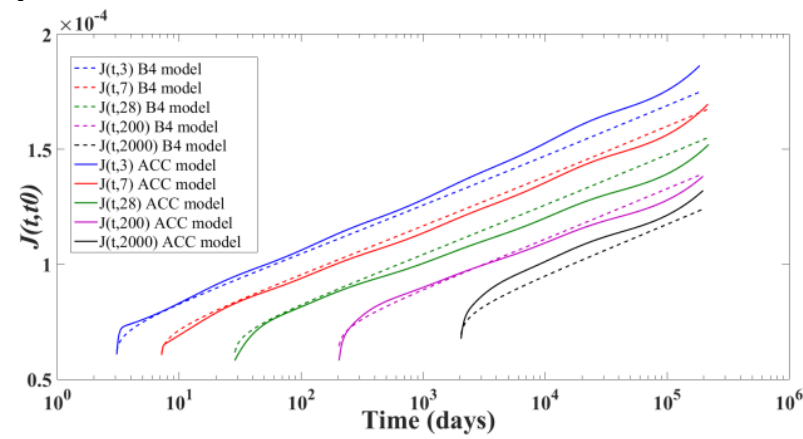

Figure 2: Comparison between ACC and B4 models creep curves.

\subsection{Numerical implementation of ACC for structural analysis}

Upon insertion of the Dirichlet series expansion (Eq. (2)) and considering that $d \sigma\left(t_{0}\right)=\frac{d \sigma\left(t_{0}\right)}{d t_{0}} d t_{0}=\dot{\sigma}\left(t_{0}\right) d t_{0}$, Eq. (1) results in [25]:

$$
\begin{aligned}
& \varepsilon(t)= \\
& \int_{0}^{t}\left[\frac{1}{E_{s}\left(t_{0}\right)}+\sum_{\mu=1}^{N} \frac{1}{E_{\mu}\left(t_{0}\right)}\left(1-e^{-\frac{\left(t-t_{0}\right)}{\tau_{\mu}}}\right)\right] \cdot \dot{\sigma}\left(t_{0}\right) d t_{0} \\
& +\varepsilon_{0}(t)
\end{aligned}
$$

Rearranging Eq. (7), leads to:

$$
\begin{aligned}
& \varepsilon(t)=\int_{0}^{t}\left[\frac{1}{E_{s}\left(t_{0}\right)}+\sum_{\mu=1}^{N} \frac{1}{E_{\mu}\left(t_{0}\right)}\right] \cdot \dot{\sigma}\left(t_{0}\right) d t_{0} \\
& -\sum_{\mu=1}^{N} \varepsilon_{\mu}^{*}(t)+\varepsilon_{0}(t)
\end{aligned}
$$

with:

$$
\varepsilon_{\mu}^{*}(t)=e^{-\frac{t}{\tau_{\mu}}} \int_{0}^{t} e^{\frac{t_{0}}{\tau_{\mu}}} \cdot \frac{1}{E_{\mu}\left(t_{0}\right)} \cdot \dot{\sigma}\left(t_{0}\right) d t_{0}
$$

where $\varepsilon_{\mu}^{*}(t)$ may be considered as a hidden state variable that represents the past history. The time $t$ can be subdivided into $F$ discrete times $t_{0}, t_{1}, \ldots, t_{F}$, with time steps given by $\Delta t_{n}=t_{n}-t_{n-1}$. By considering that $\dot{\sigma}\left(t_{0}\right)$ and $E_{\mu}\left(t_{0}\right)$ remain constant within each time step $\Delta t_{n}$, Eq. (9) can take the form [25]:

$$
\varepsilon_{\mu}^{*}\left(t_{n}\right)=e^{-\frac{t_{n}}{\tau_{\mu}}} \sum_{s t=1}^{n} \frac{\dot{\sigma}\left(t_{s t}\right)}{E_{\mu}\left(t_{s t}^{*}\right)} \cdot \int_{t_{s t-1}}^{t_{s t}} e^{-\frac{t_{0}}{\tau_{\mu}}} d t_{0}
$$

with $t_{s t} \leq t_{s t}^{*} \leq t_{s t+1}$, using a generalized midpoint rule. Eq. (10) can be exactly integrated, yielding [25]:

$$
\begin{aligned}
& \varepsilon_{\mu}^{*}\left(t_{n}\right)= \\
& e^{-\frac{t_{n}}{\tau_{\mu}}} \sum_{s t=1}^{n}\left(e^{-\frac{t_{s t}}{\tau_{\mu}}}\left(1-e^{-\frac{\Delta t_{s t}}{\tau_{\mu}}}\right) \frac{\tau_{\mu} \Delta \sigma\left(t_{s t}\right)}{\Delta t_{s t} E_{\mu}\left(t_{s t}^{*}\right)}\right)
\end{aligned}
$$

Based on Eq. (11), a recurrent formula can be defined to express the hidden state variable value at time $t_{n}$, based on its value in the preceding time step $t_{n-1}$, which avoids the need to store the hidden variable value at each time step, namely [25]:

$$
\begin{gathered}
\varepsilon_{\mu}^{*}\left(t_{n}\right)= \\
\left(1-e^{-\frac{\Delta t_{n}}{\tau_{\mu}}}\right) \frac{\tau_{\mu} \Delta \sigma\left(t_{n}\right)}{\Delta t_{n} E_{\mu}\left(t_{n}^{*}\right)}+\varepsilon_{\mu}^{*}\left(t_{n-1}\right) e^{-\frac{\Delta t_{n}}{\tau_{\mu}}} \\
\mu=1, \ldots, N
\end{gathered}
$$

Eq. (12) evidences that in order to determine the value of the hidden variable of each Kelvin chain $\varepsilon_{\mu}^{*}\left(t_{n}\right)$ for the time $t_{n}$, there is only the need to know (or store) its value from the preceding time step $\varepsilon_{\mu}^{*}\left(t_{n-1}\right)$. This procedure is very convenient for implementation in FEM software for the analysis of creep problems of large structures. The initial value of the state variable is determined from:

$$
\varepsilon_{\mu}^{*}\left(t_{1}\right)=\frac{\Delta \sigma\left(t_{1}\right)}{E_{\mu}\left(t_{1}\right)}
$$

Based on Eq. (8), it is possible to derive the total incremental strain $\Delta \varepsilon\left(t_{n}\right)$ in each time step $\Delta t_{n}[25]:$

$$
\begin{aligned}
& \Delta \varepsilon\left(t_{n}\right)=\left[\frac{1}{E_{s}\left(t_{n}^{*}\right)}+\sum_{\mu=1}^{N} \frac{1}{E_{\mu}\left(t_{n}^{*}\right)}\right] \cdot \Delta \sigma\left(t_{n}\right) \\
& -\sum_{\mu=1}^{N} \Delta \varepsilon_{\mu}^{*}\left(t_{n}\right)+\Delta \varepsilon_{0}\left(t_{n}\right)
\end{aligned}
$$

with $t_{n-1} \leq t_{n}^{*} \leq t_{n}$, using a generalized midpoint rule.

The incremental value of the state variable $\Delta \varepsilon_{\mu}^{*}\left(t_{n}\right)$ can be expressed by: 


$$
\begin{aligned}
& \Delta \varepsilon_{\mu}^{*}\left(t_{n}\right)=\varepsilon_{\mu}^{*}\left(t_{n}\right)-\varepsilon_{\mu}^{*}\left(t_{n-1}\right)= \\
& \left(1-e^{-\frac{\Delta t_{n}}{\tau_{\mu}}}\right) \frac{\tau_{\mu} \Delta \sigma\left(t_{n}\right)}{\Delta t_{n} E_{\mu}\left(t_{n}^{*}\right)}+\varepsilon_{\mu}^{*}\left(t_{n-1}\right)\left(e^{-\frac{\Delta t_{n}}{\tau_{\mu}}}-1\right)
\end{aligned}
$$

By introducing Eq. (15) into (Eq. (14) leads to:

$$
\begin{aligned}
& \Delta \varepsilon\left(t_{n}\right)= \\
& {\left[\frac{1}{E_{s}\left(t_{n}^{*}\right)}+\sum_{\mu=1}^{N} \frac{1}{E_{\mu}\left(t_{n}^{*}\right)}\left(1-\left(1-e^{-\frac{\Delta t_{n}}{\tau_{\mu}}}\right) \cdot \frac{\tau_{\mu}}{\Delta t_{n}}\right)\right] \cdot \Delta \sigma\left(t_{n}\right)} \\
& -\sum_{\mu=1}^{N} \varepsilon_{\mu}^{*}\left(t_{n-1}\right)\left(e^{-\frac{\Delta t_{n}}{\tau_{\mu}}}-1\right)+\Delta \varepsilon_{0}\left(t_{n}\right)
\end{aligned}
$$

By arranging Eq. (16), a fictitious linear elastic stress-strain law can be obtained [25]:

$$
\Delta \varepsilon\left(t_{n}\right)=\frac{\Delta \sigma\left(t_{n}\right)}{\bar{E}\left(t_{n}\right)}+\Delta \bar{\varepsilon}\left(t_{n}\right)+\Delta \varepsilon_{0}\left(t_{n}\right)
$$

where $\bar{E}\left(t_{n}\right)$ represents a pseudo-instantaneous elastic modulus, and $\Delta \bar{\varepsilon}\left(t_{n}\right)$ represents a pseudo-inelastic strain increment [25]:

$$
\begin{aligned}
& \frac{1}{\bar{E}\left(t_{n}\right)}=\frac{1}{E_{s}\left(t_{n}^{*}\right)}+ \\
& \sum_{\mu=1}^{N} \frac{1}{E_{\mu}\left(t_{n}^{*}\right)}\left[1-\left(1-e^{-\frac{\Delta t_{n}}{\tau_{\mu}}}\right) \frac{\tau_{\mu}}{\Delta t_{n}}\right] \\
& \Delta \bar{\varepsilon}\left(t_{n}\right)=\sum_{\mu=1}^{N} \varepsilon_{\mu}^{*}\left(t_{n-1}\right)\left(1-e^{-\frac{\Delta t_{n}}{\tau_{\mu}}}\right)
\end{aligned}
$$

From Eq. (17), the material stress-strain constitutive relation can be derived:

$$
\Delta \sigma\left(t_{n}\right)=\bar{E}\left(t_{n}\right) \cdot\left[\Delta \varepsilon\left(t_{n}\right)-\Delta \bar{\varepsilon}\left(t_{n}\right)-\Delta \varepsilon_{0}\left(t_{n}\right)\right]
$$

Considering that $\bar{\sigma}\left(t_{n}\right)=-\bar{E}\left(t_{n}\right) \Delta \bar{\varepsilon}\left(t_{n}\right)$, Eq. (20) can be rewritten as:

$$
\Delta \sigma\left(t_{n}\right)=\bar{E}\left(t_{n}\right) \cdot\left[\Delta \varepsilon\left(t_{n}\right)-\Delta \varepsilon_{0}\left(t_{n}\right)\right]+\bar{\sigma}\left(t_{n}\right)
$$

The multiaxial generalization of the problem can be obtained by introducing the matrix $\underline{C}$ that relates the stress and strains components of the material. Introducing the matrix $\underline{C}$ in Eq. (17) leads to:

$$
\Delta \underline{\varepsilon}\left(t_{n}\right)=\frac{\underline{C} \Delta \underline{\sigma}\left(t_{n}\right)}{\bar{E}\left(t_{n}\right)}+\Delta \underline{\bar{\varepsilon}}\left(t_{n}\right)+\Delta \underline{\varepsilon}_{0}\left(t_{n}\right)
$$

Assuming that the matrix $\underline{D}=\underline{C}^{-1}$, the multiaxial generalization of Eq. (21) and Eq. (12) take the form:

$$
\begin{aligned}
& \Delta \underline{\sigma}\left(t_{n}\right)=\bar{E}\left(t_{n}\right) \underline{D}\left[\Delta \underline{\varepsilon}\left(t_{n}\right)-\Delta \underline{\varepsilon}_{0}\left(t_{n}\right)\right]+\bar{\sigma}\left(t_{n}\right) \\
& \underline{\varepsilon}_{\mu}^{*}\left(t_{n}\right)=\left(1-e^{-\frac{\Delta t_{n}}{\tau_{\mu}}}\right) \frac{\tau_{\mu} \underline{C} \Delta \underline{\sigma}\left(t_{n}\right)}{\Delta t_{n} E_{\mu}\left(t_{n}^{*}\right)}+\underline{\varepsilon}_{\mu}^{*}\left(t_{n-1}\right) e^{-\frac{\Delta t_{n}}{\tau_{\mu}}}
\end{aligned}
$$

with $\overline{\bar{\sigma}}\left(t_{n}\right)=-\bar{E}\left(t_{n}\right) \Delta \underline{\bar{\varepsilon}}\left(t_{n}\right)$.

For the tridimensional case, the compliance matrix $\underline{C}$ is given by [32]:

$$
\underline{C}=\left[\begin{array}{cccccc}
1 & -v & -v & 0 & 0 & 0 \\
-v & 1 & -v & 0 & 0 & 0 \\
-v & -v & 1 & 0 & 0 & 0 \\
0 & 0 & 0 & 2(1+v) & 0 & 0 \\
0 & 0 & 0 & 0 & 2(1+v) & 0 \\
0 & 0 & 0 & 0 & 0 & 2(1+v)
\end{array}\right]
$$

where $v$ is the Poisson coefficient. In order to perform accurate numerical simulations of creep sensitive structures, it is necessary to adopt a creep compliance prediction model that can simulate the aging effect of CBM. As presented in Eq. (18), in every time step $\Delta t_{n}$ it is necessary to supply the moduli of each Kelvin chain $E_{\mu}\left(t_{n}^{*}\right)$ for $\mu=1, \ldots, N$ and $E_{s}\left(t_{n}^{*}\right)$. This can be performed via the creep compliance prediction models, as B4 [29], that can return $J\left(t_{j}, t_{n}^{*}\right)$, with $t_{j} \geq t_{n}^{*}$. In the absence of analytical expressions, the evaluation of the Kelvin chains modulus can be performed with a nonnegative least-square method [33], [34], where the moduli $E_{\mu}\left(t_{n}^{*}\right)$ of each chain are determined, given that the appropriate retardation times $\tau_{\mu}$ are provided. The ACC model was implemented into FEMIX, with the code designation of NLMM174, where NLMM means Non-Linear Material Model.

\subsection{Integrating ACC with thermo- mechanical models}

The creep, shrinkage and thermal models are integrated with the $3 \mathrm{D}$ multidirectional fixed smeared crack model (MFSCD) described elsewhere [22] in order to be possible the simulation of the most relevant time dependent phenomena in cracked concrete structures. 
According to the MFSCD, at the level of an integration point (IP) of a generic solid finite element, the increment of total strain in a cracked concrete can have the following incremental strain components:

$$
\begin{aligned}
& \Delta \underline{\varepsilon}(t)=\Delta \underline{\varepsilon}^{e}(t)+\Delta \underline{\varepsilon}^{c r}(t)+\Delta \underline{\varepsilon}^{s}(t) \\
& +\Delta \underline{\varepsilon}^{T}(t)+\Delta \underline{\varepsilon}^{c}(t)
\end{aligned}
$$

where $\Delta \underline{\varepsilon}^{e}, \Delta \underline{\varepsilon}^{c}, \Delta \underline{\varepsilon}^{s}$ and $\Delta \underline{\varepsilon}^{T}$ are the elastic, creep, shrinkage and thermal incremental strain vectors, and $\Delta \underline{\varepsilon}^{c r}$ is the crack incremental strain vector. A nonlinear transient analysis must be performed, since the total strain is time dependent, being its components evaluated during the time.

As long as the maximum compressive stress is less than $40 \%$ of the compressive strength of the concrete, the principle of superposition effects can be applied, and the mechanical incremental strain is the addition of the elastic and concrete components:

$$
\begin{aligned}
\Delta \varepsilon^{m}(t)= & \Delta \varepsilon^{e}\left(t_{0}\right)+\Delta \varepsilon^{c}(t), \\
\Delta \varepsilon^{m}(t)= & \Delta \underline{\varepsilon}(t)-\Delta \underline{\varepsilon}^{s}(t) \\
& -\Delta \underline{\varepsilon}^{T}(t)-\Delta \underline{\varepsilon}^{c r}(t), \\
\Delta \varepsilon^{m}(t)= & \underline{\varepsilon}^{m}\left(t_{n+1}\right)-\underline{\varepsilon}^{m}\left(t_{n}\right),
\end{aligned}
$$

being $\underline{\varepsilon}^{m}\left(t_{n+1}\right)$ and $\underline{\varepsilon}^{m}\left(t_{n}\right)$ the mechanical strain vector at the time $t_{n+1}$ and $t_{n}$, respectively. The shrinkage and thermal strain components are designated as stressindependent strain.

For coupling the time dependent phenomena in consideration with the MFSCM, the following equations of this model must be taken into account [22]:

$$
\begin{gathered}
\Delta \underline{\sigma}_{\ell}^{c r}\left(t_{n}\right)=\underline{T}^{c r} \Delta \underline{\sigma}\left(t_{n}\right) \\
\Delta \underline{\varepsilon}^{c r}\left(t_{n}\right)=\left[\underline{T}^{c r}\right]^{T} \Delta \underline{\varepsilon}_{\ell}^{c r}\left(t_{n}\right) \\
\Delta \underline{\sigma}_{\ell}^{c r}\left(t_{n}\right)=\underline{D}^{c r}\left(t_{n}\right) \Delta \underline{\varepsilon}_{\ell}^{c r}\left(t_{n}\right)
\end{gathered}
$$

where $\Delta \underline{\varepsilon}_{\ell}^{c r}\left(t_{n}\right)$ and $\Delta \underline{\sigma}_{\ell}^{c r}\left(t_{n}\right)$ are the incremental crack strain and crack stress vectors in the local coordinate systems of the cracks (the number of cracks active in an IP depends on the selected crack opening criterion), $\underline{T}^{c r}$ is the matrix that transforms the stress components from the global coordinate system to the local crack coordinate system, and $\underline{D}^{c r}\left(t_{n}\right)$ is the constitutive matrix of the active cracks in the IP, which is also assumed time dependent due to the dependence of the fracture parameters when early age phenomenon and concrete maturation is intended to be simulated. Introducing Eq. (23) in Eq. (30), and (28) in (23) results in, respectively

$$
\begin{gathered}
\Delta \underline{\sigma}_{\ell}^{c r}\left(t_{n}\right)=\underline{T}^{c r}\left(\overline { E } ( t ^ { * } ) \underline { D } \left(\Delta \underline{\varepsilon}\left(t_{n}\right)\right.\right. \\
\left.-\Delta \underline{\varepsilon}^{s}\left(t_{n}\right)-\Delta \underline{\varepsilon}^{T}\left(t_{n}\right)-\Delta \underline{\varepsilon}^{c r}\left(t_{n}\right)\right) \\
\left.+\bar{\sigma}\left(t_{n}\right)\right) \\
\Delta \underline{\sigma}\left(t_{n}\right)=\bar{E}\left(t^{*}\right) \underline{D}\left[\Delta \underline{\varepsilon}\left(t_{n}\right)-\Delta \underline{\varepsilon}^{s}\left(t_{n}\right)\right. \\
\left.-\Delta \underline{\varepsilon}^{T}\left(t_{n}\right)-\Delta \underline{\varepsilon}^{c r}\left(t_{n}\right)\right]+\bar{\sigma}\left(t_{n}\right)
\end{gathered}
$$

Introducing Eqs. (31) and (32) in Eq. (33), and making some arrangements, yields

$$
\begin{aligned}
& \Delta \underline{\varepsilon}_{\ell}^{c r}\left(t_{n}\right)=\left(\underline{D}^{c r}+\underline{T}^{c r} \bar{E}\left(t^{*}\right) \underline{D}\left[\underline{T}^{c r}\right]^{T}\right)^{-1} \times \\
& \left(\underline { T } ^ { c r } \overline { E } ( t ^ { * } ) \underline { D } \left[\Delta \underline{\varepsilon}\left(t_{n}\right)-\right.\right. \\
& \left.\left.\Delta \underline{\varepsilon}^{s}\left(t_{n}\right)-\Delta \underline{\varepsilon}^{T}\left(t_{n}\right)\right]+\underline{T}^{c r} \bar{\sigma}\left(t_{n}\right)\right)
\end{aligned}
$$

By including Eq. (35) in (31), it is obtained

$$
\begin{aligned}
& \Delta \underline{\varepsilon}^{c r}\left(t_{n}\right)=\left[\underline{T}^{c r}\right]^{T}\left[\left(\underline{D}^{c r}+\right.\right. \\
& \left.\underline{T}^{c r} \bar{E}\left(t^{*}\right) \underline{D}\left[\underline{T}^{c r}\right]^{T}\right)^{-1} \times \\
& \left(\underline { T } ^ { c r } \overline { E } ( t ^ { * } ) \underline { D } \left[\Delta \underline{\varepsilon}\left(t_{n}\right)-\right.\right. \\
& \left.\left.\left.\Delta \underline{\varepsilon}^{s}\left(t_{n}\right)-\Delta \underline{\varepsilon}^{T}\left(t_{n}\right)\right]+\underline{T}^{c r} \bar{\sigma}\left(t_{n}\right)\right)\right]
\end{aligned}
$$

and then introducing this last equation in Eq. (34) and making some operations, the incremental stress vector is determined:

$$
\begin{aligned}
& \Delta \underline{\sigma}\left(t_{n}\right)=\left(\underline{I}-\bar{E}\left(t^{*}\right) \underline{D}\left[\underline{T}^{c r}\right]^{T}\left(\underline{D}^{c r}+\right.\right. \\
& \left.\left.\underline{T}^{c r} \bar{E}\left(t^{*}\right) \underline{D}\left[\underline{T}^{c r}\right]^{T}\right)^{-1} \underline{T}^{c r}\right) \times \\
& \left(\overline { E } ( t ^ { * } ) \underline { D } \left(\Delta \underline{\varepsilon}\left(t_{n}\right)-\Delta \underline{\varepsilon}^{s}\left(t_{n}\right)-\right.\right. \\
& \left.\left.\Delta \underline{\varepsilon}^{T}\left(t_{n}\right)\right)+\bar{\sigma}\left(t_{n}\right)\right)
\end{aligned}
$$

The incremental shrinkage strain can be obtained by one of the models described in [22], and the incremental thermal strain is 
determined from the temperature field, e.g., using the results of the thermal model described in [22]. For the three-dimensional case, these vectors are defined by

$$
\begin{aligned}
\Delta \underline{\varepsilon}^{s}\left(t_{n}\right) & =\left[\begin{array}{llllll}
\Delta \varepsilon^{s} & \Delta \varepsilon^{s} & \Delta \varepsilon^{s} & 0 & 0 & 0
\end{array}\right]^{T} \\
\Delta \underline{\varepsilon}^{T}\left(t_{n}\right) & =\left[\begin{array}{llllll}
\Delta \varepsilon^{T} & \Delta \varepsilon^{T} & \Delta \varepsilon^{T} & 0 & 0 & 0
\end{array}\right]^{T}
\end{aligned}
$$

and are obtained with.

$$
\begin{aligned}
& \Delta \underline{\varepsilon}^{s}\left(t_{n}\right)=\underline{\varepsilon}^{s}\left(t_{n+1}\right)-\underline{\varepsilon}^{s}\left(t_{n}\right) \\
& \Delta \underline{\varepsilon}^{T}\left(t_{n}\right)=\underline{\varepsilon}^{T}\left(t_{n+1}\right)-\underline{\varepsilon}^{T}\left(t_{n}\right)
\end{aligned}
$$

To solve Eq. (37) a nonlinear transient analysis must be performed, since the strain components are time dependent.

\section{MODEL APPRAISAL}

The predictive performance of the ACC at structural level is assessed by conducting a numerical simulation of a flexurally reinforced concrete (RC) beam submitted to bending up to a period of about two years. The total deformation obtained in the numerical simulations is compared with the experimental results of the beam with the reference CB-59 of experimental program conducted in [35].

The geometry, reinforcements, and test setup are presented in Figure 3. The beam is longitudinally reinforced with two $\varnothing 10$ steel bars as tensile reinforcement (average yield stress, $f_{\text {sym }}$ of $520 \mathrm{MPa}$ and average elasticity modulus, $E_{s m}$, of $194 \mathrm{GPa}$ ) and two $\varnothing 6$ steel bars as compressive reinforcement $\left(f_{\text {sym }}=525\right.$ $\mathrm{MPa}$ and $E_{s m}=183 \mathrm{GPa}$ ). Transverse reinforcements are also adopted in the form of steel stirrups placed in the entire length of the beam with a spacing of $75 \mathrm{~mm}\left(f_{\text {sym }}=212 \mathrm{MPa}\right.$ and $E_{s m}=200 \mathrm{GPa}$ ).

According to [35] the concrete used to cast the beam had a cement content of $394 \mathrm{~kg} / \mathrm{m}^{3}$ (ordinary Portland cement), a water-cement ratio of 0.53 and an aggregate-cement ratio of 4.56. The concrete cube's compressive strength, Young's modulus, and flexural tensile strength at 28 days of age was, respectively, $40 \mathrm{MPa}, 27.2 \mathrm{GPa}$, and 4.67MPa [35].

After casting, the beam was stored in the laboratory, staying covered with wet burlap bags for 7 days. The beam was loaded 28 days after has been cast, according to the test setup presented in Figure 3. The loads were applied using concrete blocks and steel plates at four points along the beam span $(1800 \mathrm{~mm})$. The total applied load is equal to $15.8 \mathrm{kN}$ ( $F=3.95 \mathrm{kN}$ ), which corresponds to a load level equal to $59 \%$ of the computed ultimate flexural capacity of the beam [35].

The midspan deflection of the beam was taken as the average of two dial gauges placed in a fixed reference frame, with the readings being regularly recorded up to a period of about two years [35].

To perform the numerical simulations of the creep flexural test, a finite element model of the concrete beam was formed with 20-node solid elements, while the steel reinforcements were discretized by 3-node linear elements. For the

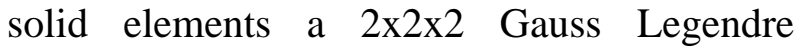
integration (GLI) scheme was adopted, while for the steel linear elements were adopted 2 integration points with the GLI technique. Due to the symmetry of the beam, only half-length of the beam is simulated. A total of 1008 solid elements and 224 linear elements are used to simulate the RC beam. The lateral view of the finite element mesh is presented in Figure 4.

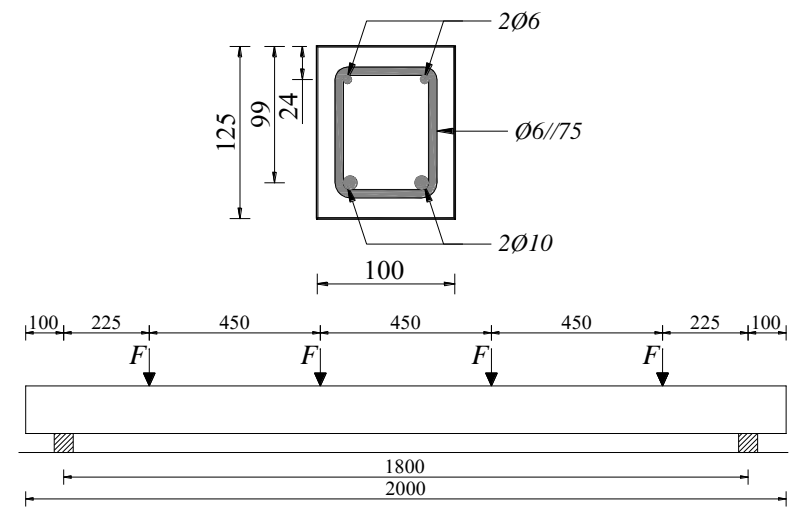

Figure 3: Beam geometry, reinforcement, support and loading configuration (dimensions in $\mathrm{mm}$ ) [35].

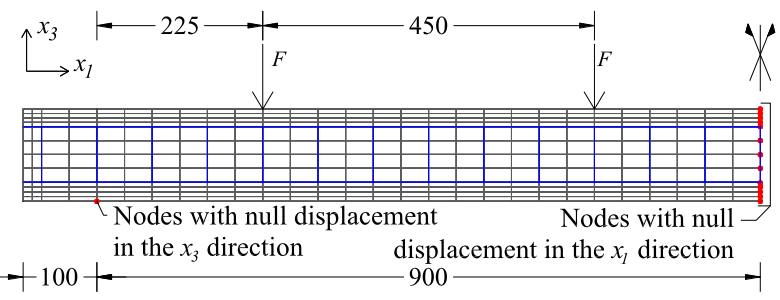

Figure 4: Finite element mesh: line elements in blue line; solid elements in black line; supports in red circles (dimensions in $\mathrm{mm}$ ). 
For the simulation of the concrete aging creep behavior is adopted the NLMM174 model, described in the previous section. Due to the inexistence of creep compliance curves for the concrete mixture studied in [35], the B4 model is employed to predict the creep behavior of the concrete, based on its mix proportions. The creep compliance curves are then considered to determine the ACC model coefficients that are used in the NLMM174 model. In Figure 5 is presented the creep compliance curves $J\left(t, t_{0}\right)$ for four loading ages $\left(t_{0}=\{21,28,56,120\}\right.$ days $)$, determined by the B4 model and by the NLMM174 creep model. The estimated NLMM174 creep functions were obtained considering 7 Kelvin chains with the retardation times

$\tau=\{0.001 ; 0.01 ; 0.1 ; 1 ; 10 ; 100 ; 1000\}$ days, the Young's modulus $E_{0}\left(t_{0}=21\right.$ days $)=26949 \mathrm{MPa}$,

$E_{0}\left(t_{0}=28\right.$ days $)=27200 M P a$,

$E_{0}\left(t_{0}=56\right.$ days $)=27682 \mathrm{MPa}$ and

$E_{0}\left(t_{0}=120\right.$ days $)=28057 \mathrm{MPa}$, and a factor $\lambda=1.0$

In addition, the creep model is combined with the MFSCM [36] to simulate the cracking phenomenon. For this purpose, the postcracking tensile capacity of the concrete is simulated by adopting the trilinear diagram presented in Figure 6, where the following parameters were taking for its definition: $f_{c t}$ $=2.81 \mathrm{MPa} ; G_{F}=0.142 \mathrm{~N} / \mathrm{mm}$ (mode I fracture energy) $\xi_{1}=0.2 ; \alpha_{1}=0.2 ; \xi_{2}=0.4 ; \alpha_{2}=0.15$. The concrete tensile strength $\left(f_{c t}\right)$ was calculated with the equation proposed in MC2010 that relates the flexural tensile strength and the tensile strength, by considering $h_{b}=100 \mathrm{~mm}$, and the concrete post-cracking diagram and value of $G_{F}$ were also determined according to the recommendations of MC2010 for plain concrete [15]. For bridging the concepts of crack width and crack strain in the context of MFSCM, and therefore ensure results independent of the finite element mesh refinement, a crack bandwidth equal to the cubic root of the integration point's volume was considered. For the shear stress-strain relationship was adopted the concept of shear retention [22], considering a cubic degradation of the fracture mode II modulus with the increase of crack normal strain.

For the compressive behavior of concrete, considering the relatively small load level that the beam is submitted, is considered in linearelastic stage. For the same reason, it was also admitted a linear-elastic response to simulate the steel reinforcements elements, assuming $E_{s}=200 G P a$ and $v_{s}=0.30$.

The concrete shrinkage deformation is not considered, as this phenomenon is particularly relevant for the analysis of early age problems, and for the loading age adopted in the creep test $\left(t_{0}=28\right.$ days $)$, it is expected to have a minor impact in the obtained results.

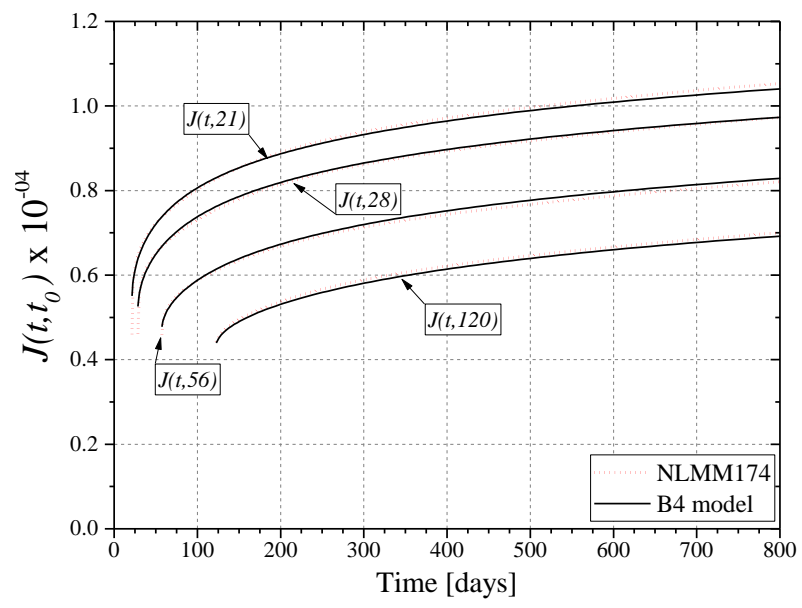

Figure 5: Comparison between the creep compliance curves obtained by the B4 model and by the NLMM174 model for the concrete studied in [35].

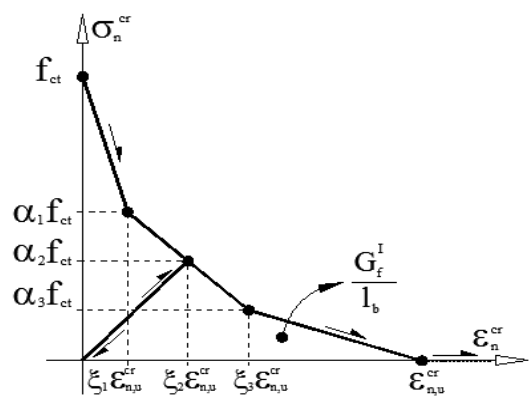

Figure 6: Trilinear tensile-softening diagram.

A transient analysis was performed considering that the loads of creep tests are applied at the age of 28 days, and the deformation of the beam, considering the concrete creep and cracking, is obtained for the subsequent time steps up to the age of 750 days. During the analysis is considered the selfweight of the beam and the loads applied during 
the creep test. The latter are simulated as line loads applied along the width of the beam's cross section, with a value of $F=39.5 \mathrm{~N} / \mathrm{mm}$.

In Figure 9 the instantaneous deformation of the beam $\left(t_{0}=28\right.$ days $)$ and at $t=750$ days are compared.

The instantaneous midspan deflection reported in [35] was about $6.70 \mathrm{~mm}$, which was about $\Delta_{\text {ins }}=1.11 \mathrm{~mm}$ higher than the maximum vertical displacement obtained in the numerical simulation $(\delta=5.59 \mathrm{~mm})$. The discrepancy between the experimental and numerical results can be justified by the apparatus used to register the beam deformation during the experimental program, which does not register the deformation of the beam's reaction structure, as well as the settlement of the beam's supports.

In Figure 10 is plotted the evolution of the midspan deflection of the beam with time. In addition to the experimental results of [35] and the obtained results from the numerical simulation, it is also plotted a curve that increases the numerically obtained midspan deflection by adding the difference between the experimental and numerical instantaneous midspan deflection $\left(\Delta_{\text {ins }}=1.11 \mathrm{~mm}\right)$. As can be seen, by adding $\Delta_{\text {ins }}$, which seems adequate due to the previous pointed-out reasons, is achieved a good agreement between the numerical response and the experimental results.

The maximum stress level at the time $t=750$ days in the longitudinal tensile and compressive reinforcement corresponds to $47.3 \%$ and $31.4 \%$ of the steel yield strength, while the maximum tensile stress in the transverse reinforcement corresponds to $7.7 \%$ of its yield strength.

In Figure 11 is displayed the crack pattern obtained from the numerical model at the instant of loading ( $t=28$ days $)$ and at $t=750$ days.
It is possible to verify that a significant number of concrete elements are cracked at the instant of loading. During the transient analysis, until $t=750$ days , it is verified the localization of crack opening characterized by the progressive opening of some of the cracks, while some others cracks started to close. The maximum computed crack width (evaluated as the product of the maximum normal crack strain with the crack bandwidth) for a solid element in the midspan zone of the finite element mesh is about $0.034 \mathrm{~mm}$ after loading $\left(t_{0}=28\right.$ days $)$ and increases about $1.85 \mathrm{x}$ at $t=750$ days $(0.063 \mathrm{~mm})$ due to the consideration of concrete creep deformation between cracks.

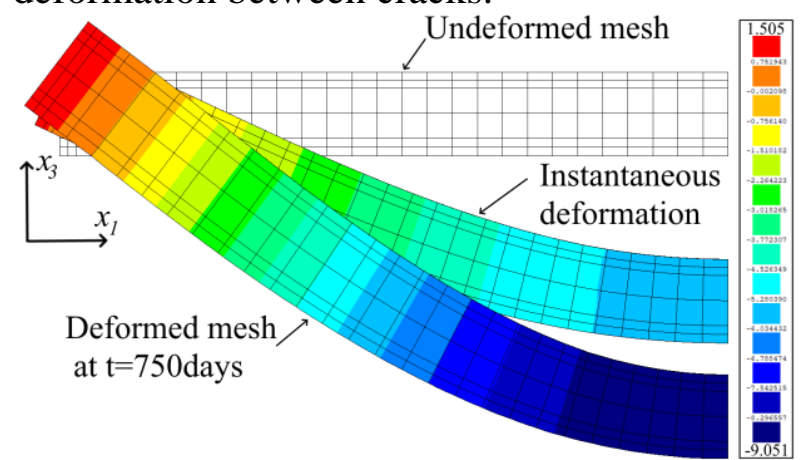

Figure 9: Displacement along $x 3$ obtained in the transient analysis (displacements in $\mathrm{mm}$, deformed meshes with 50x magnification factor).

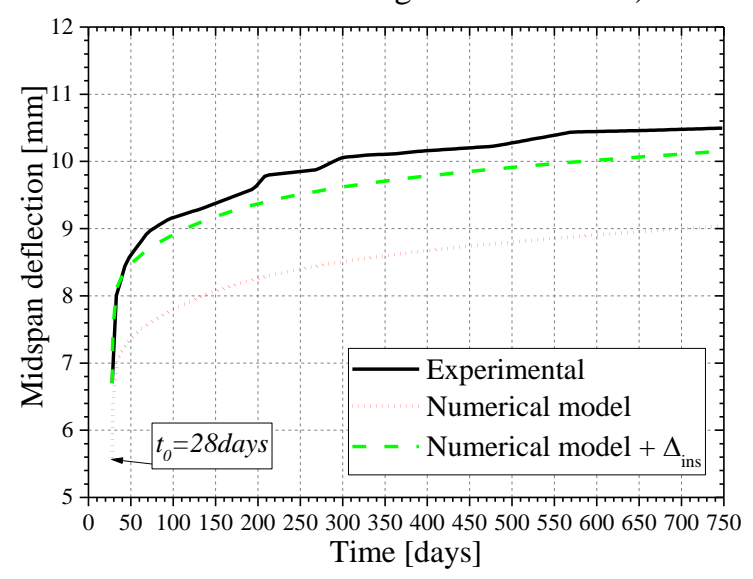

Figure 10: Evolution of midspan deflection of the reinforced concrete beam. 


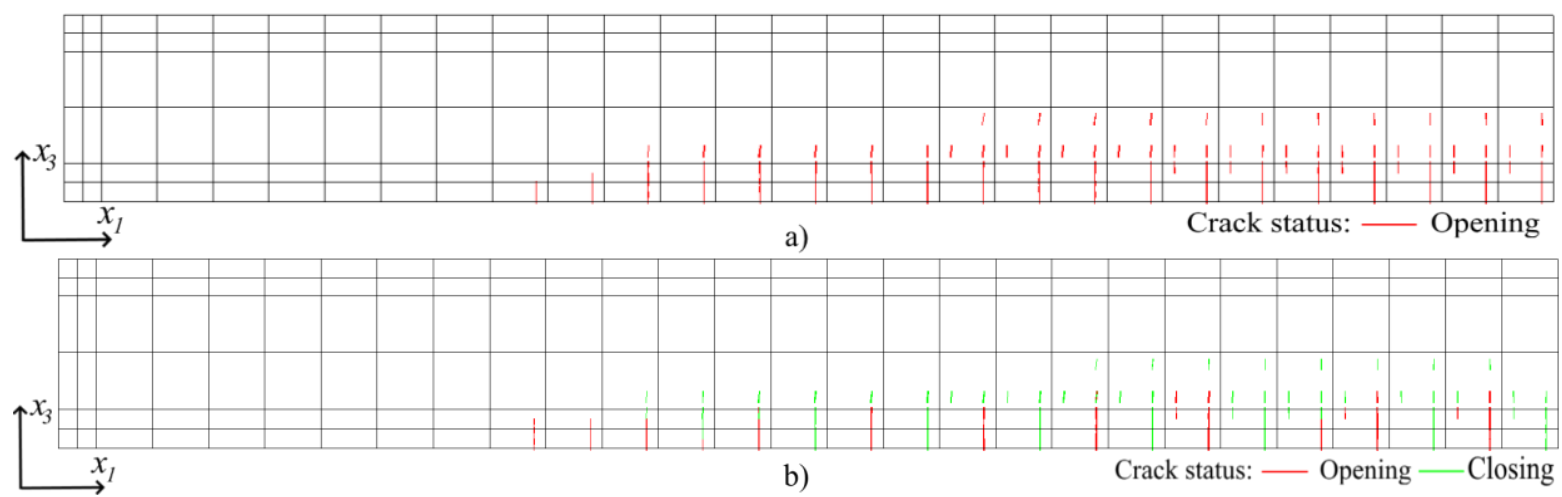

Figure 11: Crack pattern obtained in the transient analysis for: a) $t=28$ days ; b) $t=750$ days (only displayed cracks with computed crack width higher than $0.005 \mathrm{~mm}$ ).

\section{CONCLUSIONS}

The present work is mainly dedicated to the description of a new Aging Creep Compliance model (ACC) and to the assessment of its predictive performance when applied at material and structural level. The ACC is based on the Dirichlet series expansion of the DPL model, and is capable of predicting the aging creep behaviour of cement based materials (CBM) and structures, since early age. The ACC model uses different values for these coefficients in each Kelvin chain, which are obtained by a nonlinear least square method applied to the experimental creep compliance curves. The ACC model was integrated into the FEMIX computer program, with the code designation of NLMM174 (Non-Linear Material Model 174), and can be coupled to the other time depend constitutive models governing the behavior CBM since their early age up to hardened stage, like maturation, shrinkage, thermal variation and cracking.

The good predictive performance of the ACC at material level was demonstrated by simulating experimental tests of laboratory scale. For demonstrating its suitability when coupled with a cracking model, a reinforced concrete beam experimentally tested under creep loading conditions was simulated. These integrated constitutive models for simulating time depend phenomena of CBM are now being extended for fibre reinforced concrete.

\section{ACKNOWLEDGEMENTS}

The authors acknowledge the support provided by FEDER funds through the Operational Programme for Competitiveness and
Internationalization - COMPETE and by national funds through FCT (Portuguese Foundation for Science and Technology) within the scope of the project InOlicTower, POCI-010145-FEDER-016905 (PTDC/ECMEST/2635/2014). The first Author would like to acknowledge the grant SFRH/BDE/96381/2013 co-funded by CiviTest and by FCT.

\section{REFERENCES}

[1] M. Jirasek and Z. P. Bazant, "Inelastic Analysis of Structures", $1^{\text {st }}$ edition. John Wiley \& Sons Ltd, 2001.

[2] G. J. Creus, "Viscoelasticity-basic theory and applications to concrete structures", vol. 16. Springer Science \& Business Media, 2012.

[3] D. Roylance, Mechanics of Materials. Wiley, 1995.

[4] A. M. Neville, W. H. Dilger, and J. J. Brooks, Creep of plain and structural concrete. Construction press, 1983.

[5] Z. P. Bažant, "Prediction of concrete creep and shrinkage: past, present and future" Nucl. Eng. Des., vol. 203, no. 1, pp. 27-38, 2001.

[6] R. I. Gilbert and G. Ranzi, "Time-dependent behaviour of concrete structures". London; New York: Spon, 2011.

[7] N. J. Gardner, "Guide for Modeling and Calculating Shrinkage and Creep in Hardened Concrete," ACI, ACI 209.2R-08, 2008.

[8] Z. P. Bazant and R. L'Hermite, "Mathematical modeling of creep and shrinkage of concrete”. John Wiley \& Sons Ltd, 1988.

[9] P. Monteiro, "Concrete: Microstructure, Properties, and Materials". McGraw-Hill Publishing, 2006.

[10] Z. P. Bažant and S. Prasannan, "Solidification Theory for Concrete Creep. I: Formulation”, J. Eng. Mech., vol. 115, no. 8, pp. 1691-1703, 1989.

[11] Z. P. Bažant and S. Prasannan, "Solidification Theory for Concrete Creep. II: Verification and Application”, J. Eng. Mech., vol. 115, no. 8, pp. 
1704-1725, 1989.

[12] Z. P. Bažant, A. B. Hauggaard, S. Baweja, and F.-J. Ulm, "Microprestress-Solidification Theory for Concrete Creep. I: Aging and Drying Effects", J. Eng. Mech., vol. 123, no. 11, pp. 1188-1194, 1997.

[13] Z. P. Bažant, A. B. Hauggaard, and S. Baweja, "Microprestress-Solidification Theory for Concrete Creep. II: Algorithm and Verification”, J. Eng. Mech., vol. 123, no. 11, pp. 1195-1201, 1997.

[14] Z. P. Bažant and E. Osman, "Double power law for basic creep of concrete”, Matér. Constr., vol. 9, no. 1, pp. 3-11, 1976.

[15] fib-federation internationale du beton, "fib Model Code for Concrete Structures 2010”. John Wiley \& Sons, 2013.

[16] Z. P. Bazant and S. Baweja, "Creep and shrinkage prediction model for analysis and design of concrete structures- model B3", Mater. Struct., vol. 28, no. 6, pp. 357-365, Jul. 1995.

[17] R. Wendner, M. H. Hubler, and Z. P. Bažant, "The B4 Model for Multi-decade Creep and Shrinkage Prediction" in Mechanics and Physics of Creep, Shrinkage, and Durability of Concrete: A Tribute to Zdeněk P. Bažant, Cambridge, Massachusetts, 2013, pp. 429-436.

[18] R. Wendner, M. H. Hubler, and Z. P. Bažant, "Statistical justification of model B4 for multidecade concrete creep using laboratory and bridge databases and comparisons to other models" Mater. Struct., vol. 48, no. 4, pp. 815-833, Apr. 2015.

[19] Ventura-Gouveia, A.; Barros, J.A.O., Azevedo, A.F.M., "Thermo-mechanical model for the material nonlinear analysis of cement based materials", 9th International Conference on Fracture Mechanics of Concrete and Concrete Structures, FraMCoS-9, V. Saouma, J. Bolander and E. Landis (Eds), California, May 29-June 1, 2016.

[20] EC2 (2004), “Eurocode 2 - Design of Concrete Structures-Part 1-1: General rules and rules for buildings”, CEN, EN 1992-1-1, Brussels, Belgium, 225 pp.

[21] Bažant, Z.P., and Baweja, S. (2000), “Creep and shrinkage prediction model for analysis and design of concrete structures - Model B3", Adam Neville Symposium: Creep and Shrinkage-Structural Design Effects, ACI SP-194, A. Al-Manaseer (ed.), Am. Concrete Institute, Farmington Hills, Michigan, 1-3.

[22] Ventura-Gouveia, A., "Constitutive models for the material nonlinear analysis of concrete structures including time dependent effects", $\mathrm{PhD}$ thesis, University of Minho, 2011.

[23] Z. P. Bažant and R. L'Hermite, "Mathematical modeling of creep and shrinkage of concrete". John Wiley \& Sons Ltd, 1988.
[24] Z. P. Bažant, "Theory of creep and shrinkage in concrete structures: A precis of recent developments", Mech. Today, vol. 2, pp. 1-93, 1975.

[25] Z. P. Bažant and S. T. Wu, "Dirichlet series creep function for aging concrete”, J. Eng. Mech., vol. 99, no. em2, 1973.

[26] Silva, P.; Valente, T.D.S.; Azenha, M.A.D.; SenaCruz, J.M.; Barros, J.A.O., "Viscoelastic response of an epoxy adhesive for construction since its early ages: experiments and modelling”, Composites Part B: Engineering, Journal, 116, 266-277, May 2017.

[27] E. Eo, "Log Double Power Law for Concrete Creep”, 1985.

[28] P. Silva, T. Valente, and M. Azenha, "Analytical nd numerical evaluation of creep data”, Universidade do Minho. Escola de Engenharia. Departamento de Engenharia Civil, Guimarães, Portugal, 2015.

[29] RILEM Technical Committee TC-242-MDC (Zdeněk P. Bažant, chair), "RILEM draft recommendation: TC-242-MDC multi-decade creep and shrinkage of concrete: material model and structural analysis*: Model B4 for creep, drying shrinkage and autogenous shrinkage of normal and high-strength concretes with multidecade applicability”, Mater. Struct., vol. 48, no. 4, pp. 753-770, Apr. 2015.

[30] A. H. Bryant and C. Vadhanavikkit, "Creep, Shrinkage-Size, and Age at Loading Effects", Mater. J., vol. 84, no. 2, pp. 117-123, Mar. 1987.

[31] Y. Lee, S.-T. Yi, M.-S. Kim, and J.-K. Kim, "Evaluation of a basic creep model with respect to autogenous shrinkage”, Cem. Concr. Res., vol. 36, no. 7, pp. 1268-1278, Jul. 2006.

[32] Rui Póvoas, "Modelos Não-lineares de Análise e Dimensionamento", PhD Thesis, FEUP, Porto, 1991.

[33] R. Bro and S. De Jong, "A fast non-negativityconstrained least squares algorithm”, J. Chemom., vol. 11, no. 5, pp. 393-401, 1997.

[34] D. Chen and R. J. Plemmons, "Nonnegativity Constraints in Numerical Analysis", presented at the Symposium on the Birth of Numerical Analysis, 2009.

[35] K. H. Tan and M. K. Saha, "Long-Term Deflections of Reinforced Concrete Beams Externally Bonded with FRP System" J. Compos. Constr., vol. 10, no. 6, pp. 474-482, Dec. 2006.

[36] Ventura-Gouveia, A., J. A. Barros, Á. F. Azevedo, and J. Sena-Cruz, "Multi-fixed smeared $3 d$ crack model to simulate the behavior of fiber reinforced concrete structures", presented at the CCC 2008 Challenges for Civil Construction, Porto, 2008. 